\title{
Construções condicionais insubordinadas no português: usos metatextuais $^{1}$
}

\author{
Flávia Bezerra de Menezes Hirata-Vale \\ Universidade Federal de São Carlos (UFSCar), São Carlos, São Paulo, Brasil \\ flaviavale@ufscar.br
}

DOI: http://dx.doi.org/10.21165/el.v46i1.1655

\begin{abstract}
Resumo
O objetivo deste trabalho é descrever e analisar os usos de construções condicionais insubordinadas no português do Brasil e de Portugal com função metatextual. Essas construções são entendidas como "o uso convencionalizado como oração principal de orações que, à primeira vista, parecem ser orações formalmente subordinadas" (EVANS, 2007), o que significa que, embora elas apresentem uma marca de subordinação, são usadas de forma independente, sem estarem conectadas a uma oração principal. Os dados foram coletados em Corpus do Português, Corpus Brasileiro, C-Oral, CRPC, e também, quando necessário, na internet. Conclui-se que essas construções contribuem para a organização textual, expressam as atitudes dos falantes e a relação intersubjetiva entre falante e ouvinte, o que mostra o alargamento do seu escopo de aplicação, indo além do nível sintático para o nível discursivo.
\end{abstract}

Palavras-chave: construções condicionais; insubordinação; organização textual.

\section{The metatextual use of insubordinate conditional constructions in Portuguese}

\begin{abstract}
The aim of this work is to describe and to analyse the uses of insubordinate conditional constructions in Brazilian and European Portuguese with metatextual function. These constructions are seen as "the main clause conventionalized use of what, on prima facie grounds, appear to be formally subordinate clauses" (EVANS, 2007), which means that although they present a subordination mark, they are used independently, without being connected to a main clause. Data were collected in Corpus do Português, Corpus Brasileiro, C Oral, CRPC, and, when necessary, in the internet. These constructions contribute to textual organization, express the speaker's attitude and the intersubjective relation between speaker and hearer, which actually shows the widening of their scope, going beyond the syntactic level itself to the discursive level.
\end{abstract}

Keywords: conditional constructions; insubordination; textual organization.

\section{Introdução}

Muitos são os trabalhos acerca das orações subordinadas condicionais tanto no português do Brasil como no português Europeu. De um ponto de vista funcionalista, o estudo dessas orações implica considerar seu estatuto como um fenômeno discursivo, o que vem sendo proposto desde o estudo pioneiro de Matthiessen e Thompson (1988), que viam o processo de combinação de orações não apenas do ponto de vista da gramática, mas também do discurso. $\mathrm{O}$ fato de se olhar para essas construções

\footnotetext{
${ }^{1}$ Este trabalho apresenta resultados e reflexões advindos de dois projetos de pesquisa, financiados pela FAPESP (Processos 2013/24523-2 e 2016/05224-2).
} 
complexas a partir de um viés discursivo acarretou ainda que a tradicional distinção entre os processos de subordinação e de coordenação de orações fosse revista, uma vez que a separação dicotômica que se propunha, por exemplo, nas gramáticas de cunho tradicional, já não mais se adequava a uma série de fatos linguísticos que passaram a ser analisados levando em conta seu uso, em situações efetivas e reais de interação social.

Neste trabalho, analisa-se um tipo de construção que, recentemente, tem sido objeto de estudo em diversas línguas, as construções insubordinadas, mais especificamente, as condicionais insubordinadas (HIRATA-VALE, 2015). De acordo com Evans (2007), trata-se do uso convencionalizado como oração principal de uma oração que, aparentemente, seria considerada subordinada, por exemplo, em:

Edgar: Você é uma pessoa muito boa

Virgínia: Obrigada.

Edgar: Se eu não fosse tão estabanado... E se eu não tivesse todo esse... Esse passado ... (PB/Corpus Brasileiro)

(2) Comissário: Mas excelência, compreenda...

Mané Gorila: O deputado não tá dizendo que se responsabiliza?

Comissário: Se é assim... se o senhor assume a responsabilidade... o senhor que sabe! (HIRATA, 1999, p. 151)

(3) Se quiser comentar ai ôô, Apolinho! (PB/Corpus do Português)

(4) nós às vezes [...] a policia, é a policia é que implica, não é. Apanhamos assim às vezes na praça, ao pé da praça, do mercado, não é, e a policia embirra connosco e autuam-nos. Se for compras para fazer negócio, tá a perceber. Nós, por exemplo, vamos a passar ali ao campo grande, há ali um mercado, não é, se nós passarmos [...] ou se nós lá passarmos e, e apanharmos um caixote de fruta ou umas couves, ou uma... assim umas coisas, não é, a policia se tá mais em baixo mandanos parar e autuam-nos. são oitocentos e tal escudos de multa.

a: mas porquê ? (PE/CRPC/Oral/426)

(5) Lembro que uma vez me levaram pra: mostrar como eles faziam aqueles tipozinhos se eu não me

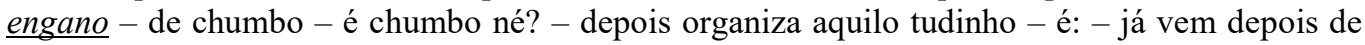
corrigido aquilo é corrigido. (PE/Corpus do Português)

(6) If you could just sit here for a while please. (EVANS, 2009, p. 1)

Se você puder sentar aqui por um momento por favor.

(7) Ob wir richtig sind? (EVANS, 2009, p. 1)

whether we right are?

'[It's possible/I doubt/you were wondering (etc.)] whether we're right?'

Se nós estamos certos?
Dat hij dat nog mocht meemaken!
CONJ he that PRT could experience
'I never thought he would live to experience this!' (VAN LINDEN, VAN DE VELDE, 2013, p. 3)
Eu nunca pensei que ele viveria uma experiência como essa.

Tomando como base critérios formais e discursivos, e partindo de corpora de textos escritos e falados, é possível notar que, no uso dessas construções, há uma extensão funcional, o que significa dizer que elas expressam relações que vão além do nível sintático, e devem ser avaliadas nos domínios semântico e pragmático (MITHUN, 2008). Nesse sentido, as funções que desempenham são também de caráter pragmático- 
textuais, e se relacionam aos componentes da situação discursiva (HEINE et al., 2013), quais sejam as atitudes do falante (crenças, compromissos), a interação entre falante $e$ ouvinte (pedidos, ofertas, ameaças) e a própria constituição do texto (funções metatextuais).

O propósito deste artigo é descrever o uso de construções condicionais insubordinadas no português, levando em consideração seu papel na constituição discursivo-textual, analisando especificamente suas funções metatextuais. Para tanto, foram acessados corpora disponíveis online. Para o português do Brasil, foram consultados o Corpus do Português (www.corpusdoportugues.org) e o Corpus Brasileiro (http://corpusbrasileiro.pucsp.br/cb/Inicial.html), e o Corpus C-Oral (www.c-oralbrasil.org). Os corpora do Português de Portugal utilizados foram o CRPC - Corpus de Referência do Português Contemporâneo (http://www.clul.ul.pt/pt/recursos/183reference-corpus-of-contemporary-portuguese-crpc), e também o Corpus do Português (www.corpusdoportugues.org). Foram utilizados, ainda, quando necessário, dados coletados na internet, por meio de busca no Google. Nos corpora, fez-se um levantamento das construções condicionais insubordinadas, e se procedeu à análise qualitativa das ocorrências encontradas. Por essa razão, não são apresentados, neste trabalho, dados quantitativos relativos às condicionais insubordinadas. As ocorrências foram classificadas segundo critérios semânticos e pragmáticos, de modo a se estabelecer uma tipologia de funções semânticas e discursivo-funcionais para $o$ português, tanto brasileiro como europeu, como, por exemplo, o fazem Vallauri (2004, 2010) para o italiano e D’Hertefelt (2015) para as línguas germânicas. Além disso, do ponto de vista formal, as construções foram analisadas segundo o seu grau de (in)dependência sintática e pragmática.

Este artigo está organizado da seguinte maneira: na seção teórica, apresentam-se os principais conceitos relacionados ao processo de insubordinação e uma breve revisão dos principais trabalhos sobre esse tema no português. Em seguida, são discutidas as características e as funções das construções insubordinadas condicionais e analisam-se as ocorrências no português do Brasil e Europeu. Por fim, apresentam-se as conclusões.

\section{Questões teóricas}

Construções como as insubordinadas, em que a oração principal não é realizada, são geralmente tratadas nas gramáticas de cunho normativo como "usos estilísticos" ou "anomalias". Para Evans (2007), isso se deve ao fato de que elas não exibem um comportamento funcional e formal que possa ser considerado como padronizado ou regular o bastante a ponto de serem abordadas em profundidade nessas obras. Evans (2007) acrescenta ainda que os casos de orações que passam por um processo de insubordinação situam-se em uma fronteira entre fala e língua, no sentido saussureano da distinção entre parole e langue, em que não é sempre claro quando, e se, a gramática emerge do discurso, o que se pode comprovar exatamente em usos de insubordinadas em contextos dialógicos.

Essas construções, entretanto, têm características sintático-semânticopragmáticas distintas das construções "completas" com se, aparecendo em contextos diferentes daqueles em que o se é usado. Nesse sentido, pode-se dizer que, no uso, o falante lança mão de muitos outros expedientes, em situações reais de interação social, para a expressão do valor condicional. 
Desse modo, quando se analisa a língua em uso, é possível perceber efetivamente que essas construções são bastante frequentes, o que vem sendo atestado em diferentes línguas, como em holandês (D'HERTEFELT; VERSTRAETE; VAN LINDEN, 2013, D'HERTEFELT, 2015); sueco e dinamarquês (VERSTRAETE; D'HERTEFELT, 2014); holandês belga (VAN LINDEN; VAN de VELDE, 2014); espanhol (GRAS, 2011; SANSIÑENA; De SMET; CORNILLIE, 2014, SANSIÑENA, 2015, GARCIA, 2016); inglês (STIRLING, 1999, HEINE et al., 2013, KALTENBÖCK, 2014), português (HIRATA-VALE, 2015, 2017) e italiano (VALLAURI, 2004, 2010).

De acordo com Evans (2007), as construções insubordinadas são aquelas que, embora ainda apresentem algumas características de uma oração subordinada, não se comportam como tal, no sentido de que elas parecem sintática, semântica e pragmaticamente completas.

Para o autor, a construção insubordinada resulta de um processo que vai desde a elipse da oração principal em uma construção anteriormente subordinada ao uso convencionalizado da oração subordinada como principal, que é então analisada como uma construção independente.

Evans (2007) elenca uma série de funções discursivas das construções insubordinadas, tais como:

1. Controle interpessoal: expressa por imperativos, pedidos, permissões, avisos e ameaças, instruções e ordens;

2. Modalização: expressa por marcadores de modalidade epistêmica, deôntica, evidencialidade, e por construções exclamativas ou avaliativas;

3. Sinalização de material pressuposto: expressa pela negação, foco contrastivo, referência cruzada, condições nas afirmações precedentes na interação, etc.

Talvez a proposta que tenha mais fortemente questionado o trabalho de Evans (2007) seja a de Mithun (2008). Depois de analisar um grande grupo de línguas, Mithun (2008) concluiu que muitas construções em Navajo e Yup'ik, por exemplo, não podem ser explicadas a partir da proposta de Evans, baseada na elipse da oração principal. E isso se dá por várias razões. Uma delas, e que é mais relevante para este trabalho, diz respeito ao fato de que a análise de Evans leva em conta, em particular, as construções completivas, que, obviamente, têm uma relação de dependência com a oração principal muito mais forte que as construções adverbiais, tendo em vista sua natureza intrinsecamente adjuntiva. Um segundo ponto mencionado por Mithun refere-se ao fato de que a lista de funções apresentadas por Evans (2007) não é realmente suficiente ou coerente com os dados por ela descritos, uma vez que eles não estão limitados ao nível sintático propriamente dito, como são os exemplos analisados por Evans (2007).

Para Mithun (2008), a insubordinação deve ser vista como um processo por meio do qual existe uma extensão funcional de marcadores de dependência gramatical do nível sintático da oração para domínios discursivos e pragmáticos mais amplos, um processo a que a autora denomina "dependency extension", ou extensão da dependência funcional. Em outras palavras, pode-se dizer que, para a autora, o que ocorre não é processo de apagamento de uma oração principal, e sim um processo discursivo por 
meio do qual uma oração anteriormente ligada, na sintaxe, a uma principal passa a ter seu funcionamento avaliado em um nível textual-discursivo.

No que diz respeito ao português, embora não haja uma caracterização das funções desses tipos de construções, como se vê para outras línguas, e conforme se pretende fazer neste trabalho, devem-se destacar alguns trabalhos que tratam desse tema, tanto para o PE como para o PB. Para o PB, consideram-se os trabalhos de Decat (1993, 1999, 2010, 2011, entre outros) e Stassi-Sé (2012). Para o PE, alguns trabalhos tratam de construções semelhantes às insubordinadas, como o de Lopes $(2009,2010)$ e o de Fonseca $(2003,2004)$.

Decat considera que essas construções são orações desgarradas, ou seja, que "ocorrem sem a oração matriz, à maneira de um enunciado independente" (DECAT, 2010, p. 167), como em:

(9) Imagine viver sem fronteiras. Poder estar sempre perto de quem você gosta. Mesmo daqueles amigos mais distantes. Imagine poder ir a qualquer lugar. E até estar em dois lugares ao mesmo tempo. Não ter limites. Não ver distâncias. Esse jeito de viver existe. Basta usar o seu celular. [...] (DECAT, 2012, p. 159).

A partir da Teoria da Estrutura Retórica (Rhetorical Structure Theory - RST), a autora adota a noção de proposição relacional, entendida como o significado implícito que emerge da combinação de duas porções de texto, sejam elas orações ou porções maiores, estejam elas marcadas por conectivos/marcadores discursivos ou não.

Stassi Sé (2012, p. 139) descreve essas construções como orações independentes, especificamente a partir do ponto de vista da Gramática DiscursivoFuncional (GDF), como em:

(10) ah, pelo menos para mim foi diferente ver assim como eles valorizam aquela cidade, como eles, embora Porto Alegre seja uma cidade bem grande, não é?, você vê como eles valorizam, como um, um turista chega lá, eles querem te mostrar "olha o rio Guaíba que co[...], passa ali, o nas[...], po[...], o nascer do sol é super, o poente é superlindo", não é (Brasil, surpresas da fotografia).

Essas construções, a que chama de subordinadas discursivas, são entendidas como grandes porções textuais, os Moves, que, apesar de apresentarem a forma de uma oração subordinada, não dependem de qualquer cláusula anterior ou posterior, e, além disso, são entonacionalmente destacadas por pausas, Atos Interativos, ou por ambos. Essas orações não apresentam dependência morfossintática.

Stassi-Sé afirma que, nessas construções, se verifica uma relação entre Moves, o que a leva a propor uma alteração no Nível Interpessoal de GDF, com a criação de uma nova camada, que seria chamada 'Camada do Discurso'. Essas construções desempenham uma Função Interacional, que é diferente das funções relacionadas a outras camadas nos Níveis Interpessoal e Representacional, tais como as funções retóricas e as funções semânticas. Assim, segundo a autora

[...] as construções introduzidas por porque representam a Função Interacional Transição, que organiza o discurso em relação à apresentação de novos conteúdos; 2) as construções introduzidas por apesar de (que), embora (que), mesmo (que) representam a Função Interacional Adendo, que atua na organização do discurso, acrescentando informação contrastiva em relação ao conteúdo que vinha sendo desenvolvido; 3 ) as 
construções introduzidas por como representam a Função Interacional Resgate, que orienta o monitoramento da interação, já que o falante busca resgatar na memória do ouvinte informações dadas; e 4) as construções iniciadas por se representam a Função Interacional Salvaguarda, que também atua no monitoramento da interação, propiciando a preservação da face do falante frente a algo que ele introduziu no discurso. (STASSI-SÉ, 2012, p. 14, grifo meu).

Lopes $(2009,2010)$ apresenta uma descrição das construções condicionais nãocanônicas no português europeu contemporâneo. Embora a autora não mencione o processo de insubordinação e nem mesmo considere que essas construções sejam insubordinadas ou independentes, a partir do exame das características formais e funcionais por ela apresentadas, pode-se dizer que se trata de construções semelhantes às que ora se analisa.

(11) Diga-me o seu nome, se faz favor/se não se importa.

(12) "Estás a fazer o quê? se não é muita indiscrição" [CRPC]

(13) Se me permite, discordo frontalmente da sua opinião.

(14) Se me é permitido intervir/ se posso interrompê-lo/ se me dá licença, gostaria de pedir um esclarecimento. (LOPES, 2010, p. 163-164).

A autora faz uma análise pragmático-funcional de construções com se que, segundo ela, não são tratadas nas gramáticas de referência do português de Portugal ou mesmo em trabalhos de linguistas portugueses sobre as condicionais. Lopes (2009, 2010) propõe uma tipologia baseada em critérios de natureza formal e funcional e centra sua análise em condicionais a que chama de enunciativas, que são mais bem compreendidas nos domínios pragmático e retórico. Dentre essas construções estão as condicionais de cortesia.

Fonseca $(2003,2004)$, por sua vez, descreve orações comparativas condicionais, dentre elas as independentes.

(15) Já repetiste n vezes a mesma coisa. Como se eu fosse surdo!

(16) Como se eu tivesse paciência para te aturar!

(17) Começa a chover. Isto é, se não estava a chover antes. As luzes das lojas e dos candeeiros parecem novinhas em folha. Como se estivessem a brilhar. Como se fossem estrelas ou outras coisas que não há. (CRPC) (FONSECA, 2003, p. 2).

Para o autor, essas construções são comuns na língua oral, e têm como característica a entonação exclamativa, o que revela, ainda, o fato de expressarem valores modais. Esses valores se revelam muitas vezes na forma de comentários, e por essa razão essas construções apresentam funções metadiscursivas ou metaenunciativas. Segundo Fonseca (2004, p. 3)

Fundamentalmente, esse comentário é de ordem avaliativa e inscreve-se no desenvolvimento do discurso como momento de desacordo com uma enunciação e/ou com o seu conteúdo, que são contestados - sendo que tal contestação se matiza, de modo vincado, de outros valores modais, que, na maior parte das vezes, vêm a primeiro plano. Nesta base, avulta no funcionamento discursivo das comparativas condicionais 
em referência o seu marcado carácter dialógico/interactivo - traduzido na circunstância de trazerem para o discurso uma específica conjugação de vozes, que se desenha, quase regularmente, como um conflito.

Embora os trabalhos mencionados sejam relevantes e extensos, nenhum deles se concentra exclusivamente nas construções condicionais insubordinadas. Além disso, não há nesses trabalhos a intenção de se explicar como ocorre o processo de surgimento dessas construções independentes ou desgarradas. Por fim, acredita-se que as construções condicionais não funcionam apenas como uma estratégia de preservação de face, como se depreende de Stassi-Sé (2012), mas são usadas de muitos outros modos, especificamente no que concerne às funções metatextuais. É o que se espera mostrar na seção seguinte.

\section{O uso de construções condicionais insubordinadas (CCI) no português: análise dos dados}

Como se sabe, a literatura acerca das construções condicionais é extensa, mas o foco de atenção são, normalmente, as construções "completas", encabeçadas pela conjunção se. No que diz respeito às construções condicionais insubordinadas, há trabalhos em diversas línguas, e a maioria deles trata das condicionais marcadas pelo se, com exceção de Boogaart e Verheij (2013), para o holandês. Destacam-se os trabalhos de Schwenter (1999, 2001, 2016), para o espanhol, o de Stirling (1999), para o inglês australiano, o de Vallauri (2004, 2010), para o italiano, o de D’Hertefelt $(2014,2015)$ para diferentes línguas germânicas, e o de Kaltenböck (2014), para o inglês.

Em relação ao português, em trabalho anterior, Hirata (1999) realizou uma descrição da hipotaxe adverbial condicional no português escrito do Brasil, no qual as orações condicionais que ora se chama de "construções condicionais insubordinadas" foram brevemente analisadas, como casos de orações "condicionais sem oração núcleo realizada". Argumentou-se que o falante, ao escolher certos recursos ao compor seu texto para criar determinados efeitos, nesse caso, satélites de natureza adverbial com valor condicional, prepara molduras, criando espaços mentais (FAUCONNIER, 1994) para o conteúdo das orações núcleo, que, algumas vezes ficam vazias, como nas construções condicionais sem oração núcleo realizada, ou insubordinadas, como se vê nos exemplos seguintes:

(18) Benedito: Tratem de calar a boquinha, viu? Se essa história se espalha ... (HIRATA, 1999, p. 148)

(19) Comissário: Mas excelência, compreenda...

Mané Gorila: $\mathrm{O}$ deputado não tá dizendo que se responsabiliza?

Comissário: Se é assim... se o senhor assume a responsabilidade... o senhor que sabe! (HIRATA, 1999, p. 151)

Como as ocorrências de condicionais sem oração núcleo foram encontradas em textos de natureza dramática, tais como peças de teatro ou roteiros de telenovela, considerou-se que essas construções são característica desse gênero textual, o que poderia ser explicado por seu caráter interativo, em que os interlocutores estão frente a frente e são participantes de um "jogo" dialógico. A título de comparação, seria possível dizer que não haveria muito sentido em contar com a participação do destinatário em 
textos técnicos, uma vez que, porque esses textos têm um caráter científico, o que não licenciaria o uso de construções condicionais sem a oração núcleo realizada.

$\mathrm{Na}$ análise que ora se apresenta, no entanto, defende-se que, além desses usos em contextos dialógicos, as CCIs podem ainda expressar valores relacionados aos componentes da situação discursiva, assim como proposto por Heine et al. (2013), quais sejam, as atitudes do falante (crenças, compromissos), a interação entre falante $e$ ouvinte (pedidos, ofertas, ameaças) e a própria constituição do texto (funções metatextuais). Nesses casos, é possível perceber claramente a diferença entre a construção condicional canônica "completa" e a construção insubordinada, uma vez que esta passa a codificar novos significados, relacionados, por exemplo, à modalização, à polidez, e assume especialmente um papel textual relacionado à coesão e à coerência. Por outro lado, o significado "original" condicional parece se perder quanto mais convencionalizada é a construção.

Como construções relacionadas às atitudes do falante, as CCIs são usadas para expressar significados subjetivos, como os desejos, conforme se vê nas duas próximas ocorrências:

(20) Era um cinquentão indiático, grisalho e gordo, duma cordialidade lerda e meio Paternal. Separado da espôsa legítima, que abandonara havia anos com três fillhos, vivia com a viúva dum veterinário. Entrem. Sentem. Fiquem à vontade. Não reparem os meus trajos. Se eu soubesse que o doutor vinha... Rodrigo e Chiru sentaram-se. (PB/CORPUS BRASILEIRO).

(21) Se eu pudesse guardar-te inteira no calor do meu sangue, agasalhar-te pelos invernos fora no côncavo da minha mão como se faz àquelas pequenas tartarugas que não nos parecem de todo vivas ou de todo mortas, se eu pudesse, se eu pudesse! Mas eu apenas comando um pouco o tempo, prolongo a memória e a acção das coisas - a vida, é diferente, é uma hóstia de um corpo único, de uma alma única que se recebe inteira, que se consome numa presença fechada. (PE/CORPUS DO PORTUGUÊS).

Nessas ocorrências, é possível dizer que a insubordinada condicional tem função de expressar um conteúdo que perpassa a avaliação, a conceitualização do próprio falante. Assim, em (20), o falante apresenta um desejo seu de que seus interlocutores não reparem nos seus trajes, que não devem estar apropriados a uma situação formal de visita. Em (21), o falante discorre longamente, por meio de várias insubordinadas condicionais sobre seus desejos em relação a uma mulher, de mantê-la próxima. Em ambos os casos, acredita-se que essas construções apresentam um julgamento subjetivo do falante, a respeito da verdade ou "desejabilidade" da situação, que, como tal, não precisa ser complementado por uma oração principal. Note-se que nos dois casos há o uso de recursos típicos da língua escrita que mostram a interrupção do fluxo de informação, em (20) as reticências e em (21), o ponto de exclamação, que é, de fato, característico desses tipos de construção.

No que diz respeito ao uso das CCIs em situações intersubjetivas, é possível dizer que essas construções referem-se à interação entre falante e ouvinte. Nesses casos, percebe-se que o falante está ciente da presença de seu interlocutor, e a construção insubordinada é usada para expressar ordens, pedidos, ameaças, valores que se relacionam essencialmente com as estratégias de preservação de face. 
(22) Máiquel: A nossa empresa cuida de... A nossa organização proporciona serviços pra mais de trinta empresas. Aqui está a relação delas. Se quiser ligar pra confirmar. (PB/CORPUS BRASILEIRO)

(23) O Sr. Presidente: - O Sr. Deputado Magalhães Mota pediu a palavra?

O Sr. Magalhães Mota (ASDI): - Se me der licença, Sr. Presidente. Só para lembrar que há deputados que são rigorosos no encerramento, mas também estão presentes na abertura.

O Sr. Presidente: - O Sr. Deputado tem toda a razão. Eu fiz uma referência geral, aliás, em tom manifestamente jocoso, que penso não ficar mal aqui na Assembleia. (PE/CRPC)

Em (22), encontra-se uma ocorrência que é considerada como uma das mais comuns no uso das insubordinadas condicionais no inglês, as diretivas, conforme se vê em Stirling (1999), por exemplo. Nela, o falante utiliza a oração insubordinada com a força ilocucionária de uma instrução, e nesse caso, depois da apresentação de uma empresa, o falante sugere que seu interlocutor ligue para obter mais informações. Do ponto de vista formal, nessas orações o sujeito geralmente está na segunda pessoa, e se refere a uma ação futura. Como já se mencionou, essas construções particularmente desempenham funções relacionadas à polidez, pois o falante quer que seu interlocutor faça algo, e o uso de uma oração condicional permite-lhe expressar que o seu ouvinte tem a opção de realizar seu pedido, sua instrução, ou não.

No que diz respeito à (23), percebe-se o uso explícito da condicional como um recurso discursivo relevante na interação entre os dois interlocutores, que corresponde a um pedido polido: ao pedir a palavra, o falante começa sua intervenção com uma insubordinada condicional. É possível perceber que novos sentidos pragmáticos, antes inferíveis do contexto, passam a ser codificados nessas construções, como a polidez. Segundo Heine et al. (2013), as construções insubordinadas parecem ser menos assertivas que suas contrapartes "completas", o que poderia ser explicado pelo não estabelecimento da relação de causa e consequência que se encontra necessariamente na construção subordinada prototípica.

Em relação ao uso das CCIs na organização textual, considera-se que essas orações expressam significados procedurais relacionados à situação discursiva. Nesse sentido, as CCIs esclarecem algo que foi mencionado anteriormente ou expressam comentários do falante, correções ou adendos.

Nas ocorrências (24) e (25), o falante parece usar a insubordinada condicional para reelaborar algo que foi dito anteriormente, à guisa de comentário. Em ambas as ocorrências, nas duas variedades do português, encontra-se a mesma expressão "se quiser", que é usada pelo falante com o intuito de dar a seu ouvinte uma opção para o entendimento do conteúdo do texto:

(24) - Há tempos eu ando banzando, por não poder trabalhar numa gruna que eu descobri, perto daqui, em terreno divaluto. Também se essa não tiver boa mancha, não há na Chapada outra que tenha. É perigosa, não nego; mas guirimpeiro não conhece perigo. Ainda não dei um serviço nela, porque o cobre tem sido curto, e preciso de gente de sangue nos olhos. Se quiser.

Dusá encarou-o, e disse:

- Vamos ver qual é o perigo.

- É que se deve entrar por um talhadão largo. E não há quem alcance os lá... (PB/CORPUS DO PORTUGUÊS) 
(25) JN - Presidência clubista e política activa, incompatíveis de todo em todo.

MGT - Toda a gente sabe que o dr. Santana Lopes tem, no fundo, uma paixão pela actividade política.

JN - Mas havia uma ideia, na opinião pública, se quiser, muito antes do congresso, que Santana Lopes deixaria o Sporting, a curto prazo... (PE/CORPUS DO PORTUGUÊS)

As CCIs metatextuais também são usadas como adendos, nos quais o falante faz uma ressalva ou adiciona uma informação, de modo a tornar o texto mais claro, como se pode perceber nas ocorrências seguintes:

(26) Re: A arte nos games sex, 11/11/2011 - 18:48 - Elder: arte? só se for arte da guerra, né? se é que é possivel um ser consciente ver beleza numa coisa tão feia. e me preocupa as pessoas estarem aceitando a violência com tanta naturalidade. logo logo ressuscitam o coliseu. o mma já vem preparando o terreno.. (PB/CORPUS INTERNET)

(27) A construção coletiva de um destino é a assunção de uma responsabilidade à dimensão da história... O Governo nacional, se ele quer ser nacional, deve governar pelo povo e para o povo, para os deserdados e pelos deserdados. (PE/CRPC)

Em (26), o falante está fazendo uma apreciação sobre jogos online, em resposta a um texto sobre jogos como "arte". Ao dar sua opinião, o falante expressa que não considera os jogos uma forma de arte, a não ser a arte da guerra, e acrescenta, como uma forma de ressalva, por meio de uma condicional insubordinada, não ser possível ver beleza em algo tão feio, a violência.

Na ocorrência (27), vê-se a insubordinada condicional também como uma forma de ressalva, e nesse caso o falante retoma parte do conteúdo anterior, para destacar exatamente o ponto a que ele se refere, o fato de um governo ter um caráter nacional.

Além disso, é importante mencionar o papel da condicional insubordinada em contextos dialógicos, como se vê abaixo:

(28) *THI: não / eu dei umas <traulitada com a moto hhh> //

*VAN: <até ele / né> //

*JOR: < tava com medo $>$ de andar // então / é preferível / <nũ é> //

*THI: <sabe por quê $>/ /$

*VAN: $<$ é $>/ /$

*JOR: $<$ vender $>/ /$

*VAN: $<\underline{\text { se até ele }>+}$

*JOR: $<$ ficar com o trem / depois acontece $>+$

*THI: $<$ não $>+$

*VAN: $<$ é $>/ /<$ depois acontece alguma coisa fala assim / eu / sabia e nũ $>+$

*JOR: $<$ é $>/ /$

*THI: <aí eu falei / ô yyy > //

*JOR: e acontece /(PB/CORPUS C-ORAL)

(29) INQ2 Pois.

INF Porque a cortiça sendo criada dentro de matos, é criada apertada. Quer dizer, uma cortiça [...] leva mesmo nove anos a criar, mas na mesma árvore, mas se tiver mato, cria-se, fica desta grossura, e se [...] não tiver mato, eu digo desta. Quer dizer [...] que se torna muito mais grossa. INQ2 Se não... Como é que é? Se não tiver o mato é que fica mais grossa?

INF Exactamente.

INQ2 Se tiver mais mato...

INF Torna-se mais grossa. Tem mais criação. (EP/CORPUS DO PORTUGUÊS) 
Em (28), os dois interlocutores estão conversando a respeito de motos e dos perigos envolvidos em seu uso, e comentam que outra pessoa sentiu medo de andar de moto, chegando à conclusão de que era preferível vender a moto. Nesse diálogo, o falante *VAN, na segunda linha diz "até ele", ao que *JOR completa, na linha seguinte "tava com medo". Mais à frente, *VAN novamente retoma o turno, e volta a sua fala anterior afirmando "se até ele". Percebe-se que o uso da CCI em diálogos mostra a natureza colaborativa da conversação, pois o falante espera que seu ouvinte "complete" o seu turno, quando usa uma construção sem a oração principal realizada.

Em (29), também como uma estratégia textual-discursiva, nota-se o uso de condicionais insubordinadas com uma função de encadeamento da narrativa. Os falantes estão falando sobre a criação de cortiça, e um dos interlocutores está explicando para o outro quais são as condições para que a cortiça fique mais grossa, o que acontece se não houver mato. Percebe-se assim o uso de construções condicionais completas, mas também há condicionais insubordinadas, que ajudam a encadear as partes do texto, de modo a criar um cenário hipotético, em que um falante acaba por concluir o turno do outro.

É possível perceber, então, no que diz respeito especificamente às CCIs relacionadas à organização textual, foco deste trabalho, que os significados metatextuais passam a operar não mais apenas no nível sintático, mas em contextos discursivos mais amplos. Nesses casos, considera-se que há uma extensão funcional de marcadores de dependência gramatical da sintaxe para o discurso, o que não necessariamente ocorre com as construções condicionais canônicas. Como elas estão ainda ancoradas no discurso, não podem ser consideradas como totalmente independentes, e assim não se configuram como casos de insubordinação, nos termos de Evans (2007). De todo modo, acredita-se que as CCIs que apresentam uma função metatextual cumprem um papel importante na estruturação discursiva, que se relaciona com o encadeamento narrativo (MITHUN, 2008). É o que também afirma Stirling (1999), para quem esse tipo de construção concorre para o encadeamento do raciocínio, da formulação das ideias, por parte do falante, e, portanto, não há o estabelecimento de uma relação causal, como ocorre nas construções condicionais "completas".

Assim, seguindo Mithun (2008, p. 107, tradução nossa), assume-se que essas construções

[...] são exploradas em várias funções sociais relacionando comentários, questões, respostas e ordens a situações sociais mais amplas. Os falantes podem demonstrar respeito ao marcar suas contribuições como pertinentes àquelas dos falantes anteriores, mostrando a dependência entre os turnos na conversação. Eles podem preservar a face ao retratar seus comentários como acidentais em relação ao tópico geral da conversação, no caso de não serem abordados em discussões adicionais ${ }^{2}$.

\footnotetext{
${ }^{2}[\ldots]$ are also exploited for various social functions by relating comments, questions, responses, and commands to the larger social situation. Speakers can show respect by marking their own contributions as pertinent to those of previous speakers, showing dependency across turns in conversation. They can save face by portraying their comments as incidental to the general topic of conversation, in case they are not taken up in further discussion.
} 


\section{Considerações finais}

A partir do exposto, conclui-se que as construções condicionais insubordinadas são bastante regulares nas línguas e que seu uso não se restringe apenas a contextos dialógicos de fala, mas também constituem uma importante estratégia na elaboração de narrativas.

Pode-se dizer que as CCIs têm funções não apenas ligadas à preservação de face ou à atenuação, mas têm propriedades funcionais relacionadas com a situação discursiva. Seu uso com uma função metatextual ou de organização do discurso, relacionado à estruturação dos próprios textos, revela que essas construções assumem uma função coesiva, o que de fato mostra a ampliação do escopo de funcionamento dessas construções, passando do nível sintático propriamente dito para o nível discursivo.

Além disso, considera-se que, ao longo do processo de insubordinação, as construções marcadas com a conjunção se vão perdendo gradativamente seu sentido condicional/hipotético e passam a codificar outros valores, determinados pragmaticamente. Como os usos das insubordinadas são muito frequentes em contextos dialógicos ocorre, de fato, nessas construções um processo de intersubjetivização, por meio do qual há nas palavras de Traugott (2003 apud BRINTON, 2013, tradução nossa),

[...] a expressão explícita da atenção do falante/escritor à imagem do ouvinte/leitor tanto no sentido epistêmico (ao prestar atenção às suas pretensas atitudes em relação ao conteúdo expresso), e em um sentido mais social (ao prestar atenção à sua 'face' ou 'necessidades de imagem, associadas à postura social e identidade) $)^{3}$.

\section{REFERÊNCIAS}

BOOGAART, R.; VERHEIJ, K. Als dát geen insubordinatie is! De pragmatiek van zelfstandige conditionele zinnen. In: JANSSEN, T.; NOORDEGRAAF, J. (Red.). Honderd jaar taalwetenschap. Artikelen aangeboden aan Saskia Daalder bij haar afscheid van de Vrije Universiteit. Amsterdam, St. Neerlandistiek VU \& Münster, Nodus Publikationen, 2013. p. 13-28.

DECAT, M. B. do N. "Leite com manga morre": da hipotaxe adverbial no português em uso. 1993. 287 f. Tese (Doutorado em Linguística Aplicada ao Ensino de Línguas) Pontifícia Universidade Católica de São Paulo, São Paulo, 1993.

Relações retóricas e funções textual-discursivas na articulação de orações no português brasileiro em uso. Calidoscópio, v. 8, n. 3, p. 167-173, set./dez. 2010.

. Estruturas desgarradas em língua portuguesa. Campinas: Pontes, 2011.

. Uma abordagem funcionalista para o estudo de processos linguísticos em gêneros textuais do português em uso. Revista Linguística / Revista do Programa de Pós-Graduação em Linguística da Universidade Federal do Rio de Janeiro, v. 8, n. 1, p. 150-162, jun. 2012.

\footnotetext{
${ }^{3}[\ldots]$ the explicit expression of the SP/W's attention to the 'self of addressee/reader in both an epistemic sense (paying attention to their presumed attitudes to the content of what is said), and in a more social sense (paying attention to their 'face' or 'image needs' associated with social stance and identity).
} 
D'HERTEFELT, S.; VERSTRAETE, J. C.; VAN LINDEN, A. Independent conditional clauses in Germanic languages: functional range and influence of 'subordinate' semantics. Trabalho apresentado no "Complex Sentences International Workshop (CSI)". 2013. Disponível em: <http://www.arts.kuleuven.be/ling/fest/events/np-3-2013CSI-2013>. Acesso em: 21 out. 2013.

D'HERTEFELT, S.; VERSTRAETE, J.-C. Independent complement constructions in Swedish and Danish: Insubordination or dependency shift? Journal of Pragmatics, n. 60 , p. 89-102, 2014.

D'HERTEFELT, S. Independent conditional clauses in Germanic: functional range, constructional unity and grammatical status. Coordination / Subordination in Lisbon (CSI). Lisbon, 07-09 May 2014. Disponível em: $<$ https://lirias.kuleuven.be/bitstream/123456789/432488/2/Independent+conditional+cla uses + in + Germanic.pdf>. Acesso em: 21 out. 2013.

. Insubordination in six Germanic languages. 2015. 229 f. PhD Thesis. Katholieke Universiteit Leuven, 2015.

EVANS, N. Insubordination and its uses. In: NIKOLAEVA, I. (Ed.). Finiteness. Theoretical and Empirical Foundations. Oxford: Oxford University Press, 2007. p. 366431.

FAUCONNIER, G. Mental Spaces: Aspects of Meaning Construction in Natural Language. New York: Cambridge University Press, 1994.

FONSECA, J. O funcionamento discursivo das comparativas condicionais independentes. Diacrítica, Série Ciências da Linguagem, nº 17/1, 2003. Disponível em: $<$ https://repositorioaberto.up.pt/bitstream/10216/20054/2/joaquimfonsecafuncionamento000083949.pdf $>$. Acesso em: 15 jul. 2015.

- As comparativas condicionais independentes em português. Círculo de Linguística Aplicada à Comunicação 17, fevereiro. 2004. Disponível em: $<$ http://www.ucm.es/info/circulo/no17/fonseca.htm>. Acesso em: 15 jul. 2015.

GARCIA, W. E. La prosodia de las construcciones insubordinadas conectivoargumentativas del español. 2016. 487 f. Tese. (Doutorado em Linguística) Universidade de Barcelona, 2016.

GRAS, P. Gramática de construcciones en interacción. Propuesta de un modelo y aplicación al análisis de estructuras independientes con marcas de subordinación en español. 2011. 580 f. Tese. (Doutorado em Linguística) - Universidade de Barcelona, 2011.

HEINE, B. et al. An outline of Discourse Grammar. In: BISCHOFF, S.; JENY, C. (Eds.). Reflections on Functionalism in Linguistics. Berlin: Mouton de Gruyter., 2013.

. On insubordination and cooptation. In: EVANS, N.; WATANABE, H. Dynamics of Insubordination. (Typological Studies in Language). Amsterdam, Philadelphia: Benjamins, 2016. 
HIRATA, F. B. M. A hipotaxe adverbial condicional no português escrito contemporâneo do Brasil. 1999. 231 f. Dissertação (Mestrado em Linguística e Língua Portuguesa) - Faculdade de Ciências e Letras, Universidade Estadual Paulista, Araraquara, 1999.

. O processo de insubordinação nas construções condicionais do português do Brasil. Relatório Científico de Estágio Pós-Doutoral. Katholiek Universiteit Leuven, Leuven, Bélgica, 2015.

. As construções completivas insubordinadas no português: forma e função. Relatório parcial de auxílio à pesquisa FAPESP (Processo 2016/05224-2) - Centro de Educação e Ciências Humanas, Universidade Federal de São Carlos, São Carlos, 2017.

KALTENBÖCK, G. On insubordination: form, function and Origin of insubordinate ifclauses. Paper presented at the workshop Outside the clause: Form and function of Extra-clausal constituents. 2014. Disponível em: <https://otcworkshop.univie.ac.at/fileadmin/user_upload/p_otc_workshop/Finalised_abstracts/Kalte nb\%C3\%B6ck_-_On_insubordination.pdf>. Acesso em: 13 mai. 2015.

LOPES, A. C. M. Condicionais de enunciação no Português europeu contemporâneo. CELGA, 2010. Disponível em <http:/www.uc.pt/uid/celga/agenda2010/acml>. Acesso em: 15 jul. 2015.

Contributos para o estudo de construções condicionais não canónicas no PEC. Diacrítica, 23.1, p. 149-170. 2009.

MATTHIESSEN, C., THOMPSON, S. A. The structure of discourse and subordination. In: HAIMAN, J.; THOMPSON, S. (Eds.). Clause combining in grammar and discourse. Amsterdam: John Benjamins, 1988. p. 275-329.

MITHUN, M. The extension of dependency beyond the sentence. Language, 84 (1), p. 69-119. 2008.

SANSIÑENA, M. S. An interactional approach to insubordinate complement clauses in Spanish. Phd. Dissertation. KULeuven, 2015.

SANSIÑENA, M. S.; De SMET, H.; CORNILLIE, B. B. subordinate and insubordinate. 2015b. Paths toward complementizer-initial main clauses, Journal of Pragmatics. Disponível em: <http://dx.doi.org/10.1016/j.pragma.2014.12.004>. Acesso em: 14 fev. 2015.

SCHWENTER, S. A. Pragmatics of conditional marking: implicature, scalarity and exclusivity. New York: Garland. 1999.

Expectations and (in)sufficiency: Spanish como-conditionals. Linguistics, v. 39, p. $733-60.2001$.

- Independent si-Clauses in Spanish: Functions and Consequences for Insubordination. In: EVANS, N.; WATANABE, H. (Eds.). Dynamics of Insubordination. Amsterdam: Benjamins. 2016.

STASSI-SÉ, J. Subordinação Discursiva no Português à luz da Gramática DiscursivoFuncional. 2012. 194 f. Tese (Doutorado em Estudos Linguísticos) - Instituto de Biociências, Letras e Ciências Exatas, Universidade Estadual Paulista, São José do Rio Preto, 2012. 
STIRLING, L. Isolated if-clauses in Australian English. In: LEE, D.; COLLINS, P. (Eds.). The clause in English. Amsterdam: John Benjamins, 1999. p. 275-297.

VALLAURI, E. Grammaticalization of syntactic incompleteness: free conditionals in Italian and other languages. SKY Journal of Linguistics (The Linguistic Association of Finland), 17, p. 189-215. 2004.

Free conditionals in discourse: the forming of a construction. Linguisticae Investigationes, v. 33:1, p. 50-85, 2010.

VAN LINDEN, A.; VAN DE VELDE, F. (Semi-)autonomous subordination in Dutch: Structures and semantic- pragmatic values. Journal of Pragmatics, n. 08, v. 22, p. 226250, 2013.

Recebido em: 30/08/2016

Aprovado em: 20/07/2017 